\title{
JOURNAL_RU
}

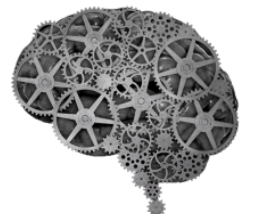

COMPANY GROUP "INTELLEKT"

Рудаков О.M.

Вятский Государственный университет

Киров, Россия

doi: 10.18411/1j2016-5-4-08

\section{Метод биометрической аутентификации, основанный на анализе клавиатурного почерка}

Сегодня стала очевидной необходимость точной идентификации людей в различных областях человеческой деятельности. Наиболее интеллектуальным подходом к решению задач идентификации является использование биометрических технологий.

Одним из вариантов биометрической аутентификации является аутентификация по клавиатурному почерку - поведенческой биометрической характеристике, важными особенностями которой являются динамика и скорость ввода определенных фраз. При применении программных методик, измерения параметров клавиатурного почерка пользователей реализуется чисто на программном уровне, без дополнительных устройств и оборудования. Статистическая обработка измеренных параметров осуществляется также на программном уровне.

В задаче идентификации пользователя по клавиатурному почерку важным этапом является обработка первичных данных. В результате этой обработки входной поток данных разделяется на ряд признаков, характеризующих те или иные качества идентифицируемой личности. В дальнейшем эти признаки, подвергаясь статистической обработке, позволяют получить ряд эталонных характеристик пользователя. 
Как показали результаты использования разработанного ранее модуля аутентификации на основе клавиатурного почерка, достоверность аутентификации при помощи выбранных параметров - скорости набора и 2-3 динамических параметров - недостаточна. Таким образом, встала необходимость провести анализ множества возможных критериев и выделить наиболее эффективные.

Для анализа были отобраны следующие критерии:

1. Среднее арифметическое удержания клавиши

2. Среднее арифметическое времени между нажатиями клавиши

3. Среднее время между нажатиями трех клавиш

4. Среднее время между нажатиями четырех клавиш

5. Среднее время между нажатиями пяти клавиш

6. Среднее время между нажатиями шести клавиш

7. Пауза между первой и второй клавишей

8. Пауза между второй и третьей клавишей

9. Пауза между третьей и четвертой клавишей

10.Пауза между четвертой и пятой клавишей

11.Пауза между пятой и шестой клавишей

12.Пауза между 6 и 7 клавишей

13.Пауза между 7 и 8 клавишей

14.Дисперсия удержания клавиши

15.Дисперсия времени между нажатиями клавиши

Количество человек, привлеченных к сбору экспериментальных данных, исчисляется несколькими десятками. За время эксперимента каждый пользователь совершил ввод контрольной фразы в привычной для него обстановке, на своей клавиатуре, что позволило снизить влияние внешних факторов.

Каждый из пользователей совершил от трех до десяти вводов контрольной фразы, в результате чего было сформировано аналогичное количество наборов 
параметров, характеризующих клавиатурный почерк, для каждого человека. В результате было собрано порядка 200 наборов параметров.

Существует несколько важных требований предъявляемых к выбранным параметрам; это такие как устойчивость значений параметров и их индивидуальность, то есть параметры почерка должны быть различны у различных пользователей.

В теории вероятности определяют статистическую устойчивость как сходимость частот значений результатов измерения физической величины. Различие индивидуальных значений признака внутри изучаемой совокупности в статистике называется вариацией признака. Для оценки разброса значений определенного параметра клавиатурного почерка использовался коэффициент вариации признака, который является критерием однородности выборки.

Также для оценки нормальности распределения значений одного параметра в выборках будем использовался t-критерий Стьюдента.

Выявление зависимостей между выбранными параметрами клавиатурного почерка позволит:

1. Определить параметры, не связанные с другими параметрами. Они в большей степени являются индивидуальными, и определяют клавиатурный почерк.

2. Определить зависимые друг от друга параметры. Это позволит, убрав дублирующиеся параметры, уменьшить сложность системы и количество вычислений.

Для анализа связности параметров используют коэффициент корреляции. Корреляционная зависимость - взаимозависимость двух или нескольких случайных величин.

По результатам оценки устойчивости параметров, т.е. разброса значений параметра, можно сделать вывод о том, что все выбранные параметры, кроме дисперсии удержания клавиши и дисперсии времени между нажатиями клавиши являются стабильными. Для данных параметров коэффициент 
вариации во всех опытах более 33\%, доверительная вероятность менее 90\%, это показывает, что колебание значений параметра значительное и что совокупность неоднородна. Для остальных параметров коэффициент вариации во всех опытах находится в интервале от $8 \%$ до $10 \%$, доверительная вероятность находится в интервале от $99 \%$ до 99,5\% , что свидетельствует о незначительном колебании параметров.

По результатам оценки корреляционных зависимостей все параметры были разделены на три группы: параметры не имеющие связь с другими параметрами, параметры имеющие сильную связь с несколькими параметрами. параметры имеющие сильную связь с большинством других параметров.

По результатам оценки корреляционных зависимостей между параметрами было выявлено, что параметры №1, 8, 9, 11, 13, 14 практически не взаимосвязаны с другими параметрами, а № 2, 3, 4, 5, 6, 7, 10, 11, 12, 15 коррелируются с другими параметрами, т.е. дополняют друг друга. И, следовательно, некоторые из них могут быть убраны.

Таким образом по результатам исследования двух методов были выделены параметры, которые определяют клавиатурный почерк. Также можно выделить и те параметры, которые по признаку устойчивости или корреляционной зависимости не являются надежными и снижают точность аутентификации пользователя.

\section{Литература:}

1. Барабанова М.И., Кияев В.И. Информационные технологии: открытые системы, сети, безопасность в системах и сетях: Учебное пособие.- СПб.: Изд-во СПбГУЭФ, 2010.- 267 с.

2. Иванов А.И. «Биометрическая идентификация личности по динамике подсознательных движений.»- Пенза: ПГУ, 2000. 